\title{
Primary care-based interventions to address the financial needs of patients experiencing poverty: a scoping review of the literature
}

\author{
Jane Parry $^{{ }^{*} \mathbb{D} \text {, Meredith Vanstone }}{ }^{2}$, Michel Grignon ${ }^{1}$ and James R. Dunn ${ }^{1}$
}

\begin{abstract}
Background: It is broadly accepted that poverty is associated with poor health, and the health impact of poverty has been explored in numerous high-income country settings. There is a large and growing body of evidence of the role that primary care practitioners can play in identifying poverty as a health determinant, and in interventions to address it.

Purpose of study: This study maps the published peer-reviewed and grey literature on primary care setting interventions to address poverty in high-income countries in order to identify key concepts and gaps in the research. This scoping review seeks to map the tools in use to identify and address patients' economic needs; describe the key types of primary care-based interventions; and examine barriers and facilitators to successful implementation.

Methods: Using a scoping review methodology, we searched five databases, the grey literature and the reference lists of relevant studies to identify studies on interventions to address the economic needs-related social determinants of health that occur in primary health care delivery settings, in high-income countries. Findings were synthesized narratively, and examined using thematic analysis, according to iteratively identified themes.

Results: Two hundred and fourteen papers were included in the review and fell into two broad categories of description and evaluation: screening tools, and economic needs-specific interventions. Primary care-based interventions that aim to address patients' financial needs operate at all levels, from passive sociodemographic data collection upon patient registration, through referral to external services, to direct intervention in addressing patients' income needs.

Conclusion: Tools and processes to identify and address patients' economic social needs range from those tailored to individual health practices, or addressing one specific dimension of need, to wide-ranging protocols. Primary carebased interventions to address income needs operate at all levels, from passive sociodemographic data collection, through referral to external services, to direct intervention. Measuring success has proven challenging. The decision to undertake this work requires courage on the part of health care providers because it can be difficult, time-consuming and complex. However, it is often appreciated by patients, even when the scope of action available to health care providers is quite narrow.
\end{abstract}

Keywords: Primary care, Poverty, Patients, Health equity, High-income country, Health care providers, Health care delivery, Scoping review

*Correspondence: parryj@mcmaster.ca

${ }^{1}$ Department of Health, Aging and Society, McMaster University, 1280 Main St West, Hamilton, ON L8S 4L8, Canada

Full list of author information is available at the end of the article

\section{Background}

The social determinants of health are defined by the World Health Organization as the "conditions in which people are born, grow, work, live and age, and the wider 
set of forces and systems shaping the conditions of daily life" [1]. It is broadly accepted that poverty is associated with poor health [2]. The influence of money on health can be examined according to multiple theories, including material mechanisms, psychosocial and behavioural pathways, and the impact of disability on income, and can be conceptualized as a combination of more than one pathway [3-9]. The health impact of poverty has been explored in numerous high-income country settings. In Canada, for example, while social policies, notably universal health insurance, attenuate the negative relationship between low income and health, those in the lowest income quintile have higher rates of chronic disease and disability, and there is some evidence that income interventions may improve health at a population level [2, 10-14]. However, whether or not health care providers and the health care system can-or even should-play a part in addressing them remains contested [15-17].

Nested within the larger societal conversation about the social determinants of individual and population health, there is an ongoing discussion happening in both the public and academic arenas about the role of primary care in addressing them [18-21]. Primary care, i.e., the services of a doctor that patients can access directly, without referral, and which are not offered in an emergency setting, is typically the first point of contact in the health care system, aiming to provide continuous, comprehensive, and coordinated care [22]. Primary care is delivered in different health care settings, and can even be in non-health sector settings, such as schools $[23,24]$. The primary care concept, according to WHO, is "a whole-of-society approach to health and wellbeing centred on the needs and preferences of individuals, families and communities. It addresses the broader determinants of health and focuses on the comprehensive and interrelated aspects of physical, mental and social health" [25]. As such, there is a strong argument that poverty, as a $\mathrm{SDOH}$, is well within the remit of primary care. Indeed, in the health care sector, primary care in particular has been a setting for interventions to address poverty [26-30].

Primary care involvement in addressing SDOH varies in both depth and scope. In terms of depth, it can be in the form of screening, with or without subsequent referral to services to address identified needs. It can extend to interventions within the primary care setting itself, beyond signposting for external supports. Social prescribing is one commonly used term for such interventions, but there is no universally accepted definition of this term, or consensus on what it encompasses [31]. While this study includes articles on social prescribing, it specifically examines interventions that aim to directly improve the client's economic circumstances. In terms of scope, such interventions can focus on a particular $\mathrm{SDOH}$ domain, such as housing [32], income [33], or education [34], or it can be broad-ranging, covering multiple SDOH and even incorporating behavioural and psycho-social aspects of individual health [35].

There are sceptics on the role of health care providers in addressing the economic needs of patients living in poverty, including those who argue that social justice is beyond the scope of medical practice [36]. There are also concerns that those who are most in need of healthcare services are the least likely to have access to them [37]. As such, interventions to address poverty could widen inequities, not narrow them [38]. Another concern is that in the process of screening for social needs, health care providers will be faced with problems that they do not have the resources to address, or will create unfulfilled expectations for patients, and may also take up time that could otherwise be spent on clinical care [39, 40]. Addressing economic needs in primary care may also distract from inadequacies in the social safety net that bring those needs into the doctor's clinic in the first place [41]. There is also evidence to suggest that even if patients disclose non-medical needs to their primary care provider, they may not want clinicians' help to address those needs [42].

These criticisms notwithstanding, there is a large and growing body of evidence to demonstrate that individual medical practitioners encounter the embodiment of poverty in their patients, and see addressing patients' socio-economic as part of their remit as health care providers, and that some health care organizations are choosing to address them [32, 43-47]. While there is a plethora of literature on various aspects of primary carebased interventions to address poverty, what is missing is an understanding of the over-arching themes that can be gleaned from this vast body of literature, such as the scope, target users and format of screening tools, and the types of interventions and what they specifically aim to address. Investigating this can also highlight areas where the field would benefit from more research.

\section{Objectives}

The purpose of this study is to map the published peerreviewed and grey literature on primary care setting interventions to address poverty in high-income countries in order to identify key concepts and gaps in the research. There are many different ways to screen for and intervene in patients' economic needs, and the inclusion criteria were deliberately constructed to capture the heterogeneity of such screening tools and interventions. Unlike previous studies, this study focuses specifically on interventions targeting economic needs, and investigates interventions in the primary care setting across the 
whole spectrum, from screening patients, collecting and managing the data generated in the process; referring patients to external services, and directly intervening to address patients' needs. In the process of examining the literature, this scoping review seeks to map the tools in use to identify and address patients' economic needs; describe the key types of primary care-based interventions; and examine barriers and facilitators to successful implementation. Its breadth of scope differentiates it from previous systematic reviews and scoping reviews, which have looked specifically at, for example, the impact of social needs interventions on health outcomes and spending [21], screening tools [48-50], social prescribing and system navigation [51-53], or which have examined SDOH more broadly [54]. This review will be global in scope, rather than concentrated on the US, as is the case in other studies [55].

\section{Methods}

The scoping review study design was selected because it is the one that is well suited to a topic where the literature is vast, complex, and heterogeneous, including theoretical and narrative reviews, and quantitative, qualitative and mixed-methods studies, peer-reviewed and grey literature $[56,57]$. The aim is to map key concepts and clarify working definitions rather than to address a precise question, such as measurable outcomes from a particular type of intervention [58]. Scoping reviews are useful for revealing the 'lay of the land' [59]. There is no universally accepted definition of what constitutes a scoping review; although there are no highly rigid structures for conducting one, a scoping review must still be systematic, reproducible and accountable [60].

This scoping review uses the six-step Arksey and O'Malley framework for conducting scoping reviews: identify the research question; identify the relevant studies; select the studies for review; chart the data; then collate, summarize and report the findings. There is an optional step to make recommendations [61]. It follows Tricco et al's Preferred Reporting Items for Systematic Reviews and Meta-Analyses extension for Scoping Reviews checklist [62].

\section{Search strategy}

\section{Selecting the literature}

For scoping reviews, the challenge is how to strike a balance between the breadth and comprehensiveness of the available literature, vs. the resources available to conduct the study [57]. This is overcome by placing limitations around the scope of the searches, guided by the research questions and an initial review of the literature, in an iterative fashion [59]. For this scoping review, search inclusion criteria were English-language published peer-reviewed and grey literature published from January 12,000 to the date of the search (between August 7 and 212,020, with the last search conducted on 21 August 2020.) For inclusion, a screening, referral or intervention paper had to include at least one of the following terms in the title or abstract: $\mathrm{SDOH}$, income, employment, food security/insecurity, housing/homelessness, legal services, education, transport and be related to the clinical health care services delivery system. Programmes had to be delivered within the primary care clinical setting, either by a health care professional, dedicated staff member or volunteer. The inclusion criteria thus targeted the search to health care setting interventions, rather than community-level interventions, or those in other settings such as welfare rights centres or schools. Studies were excluded if they did not meet these criteria, and if they were not related to economic security needs screening, referral or intervention. By searching the literature using the key words 'primary care', 'family practice' and/or 'health centre/center', it was possible to include primary care settings, which in one context would count as primary care (e.g. pediatricians in the US), that would not in another, and include settings such as community health centres, (which exist in Canada and the US, but which do not exist in the same form in the UK, for example).

Key word searches were conducted on MEDLINE, Web of Science citation indexes for science and social science, Scopus, Scholars Portal Journals, Sociological Abstracts databases, as well as grey literature searches on Open Grey, and a search of citations in key studies. The University of California, San Francisco Social Interventions Research \& Evaluation Network (SIREN) resources database was also searched. The search strategy is available in Appendix (Fig. 1).

After initial screening, full papers were reviewed and screened by one author (JP) against the inclusion criteria to determine eligibility. As this is a scoping study, not a systematic review, there was limited assessment of methodological quality. Initially all types of peer-reviewed papers were included, including qualitative, quantitative and mixed-methods studies of interventions, clinical decision-making tools, systematic and scoping reviews, and commentaries and opinion pieces. Study protocols were excluded. Any new and potentially relevant sources identified from citation lists were added. Upon review of full text, those that were then deemed outside the scope of the study were removed.

\section{Analysis}

Each study abstract was scanned first to identify main themes. This was an iterative process which required going back and forth to capture multiple themes across different papers. Once these initial themes were identified, they were 


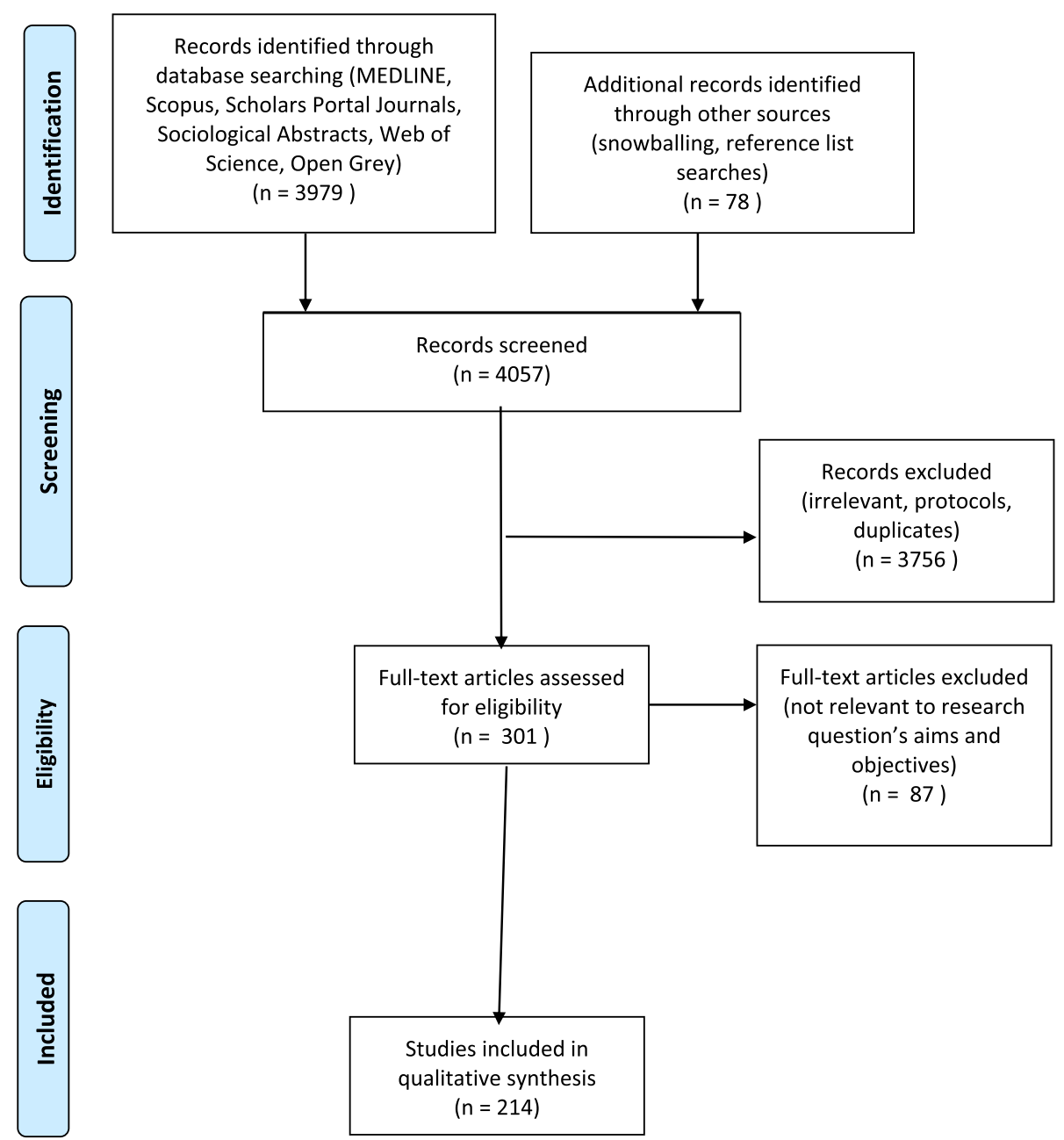

Fig. 1 PRISMA Flow diagram

grouped into the following categories: literature reviews and systematic reviews; screening tools, economic needsspecific interventions; and service facilitators and barriers. Working through each category, the papers were analyzed to find points of commonality and divergence, and to identify any new emerging themes. We adopted qualitative content analysis to explore emerging themes, collapsing and expanding them over the course of the analysis process, until logical and clear themes and sub-themes emerged. This subjective interpretation of content using a key word coding system worked well to wrangle such a large body of literature into a workable volume of analysis to understand the phenomena under study $[63,64]$.

\section{Results}

In total, the searches yielded 3979 results, and the titles and abstracts were initially screened for relevance. Duplicates were removed, and the remaining 214 were included in the review.
The following section will present the themes identified in the analysis. Unmet financial needs can be determined by the inability to access the necessities of life, in particular adequate, secure housing and stable supply of food. Financial need has been expanded to include other needs which are a direct result of inadequate finances, including stable housing and food security. It was common for papers to straddle two or more themes, for example, for one paper to include a screening tool description, service user perspectives, and to focus on food insecurity.

Analysis of this literature identified that although social needs interventions have existed for at least two decades in various forms, they have grown rapidly, as the vast bulk of the literature had been published in the past 5 years, indicating that social needs interventions are proliferating in line with a broader trend towards integrated behavioral healthcare, notably in the US and UK $[35,44$, $65,66]$. Studies of interventions use a broad range of outcome measures, including those related to process, health 
impact, costs, and service user and provider perceptions. They also use a variety of terminology to describe such interventions, such as social prescribing [67], clinicalcommunity linkages [68], and social referral [69]. The results are presented under three headings, each of which describes a different aspect of the process of financial needs intervention in primary care settings. Screening tools and screening tool evaluations covers the process of identifying patients with unmet financial need, and includes the tools themselves as well as analyses of their use and utility. Economic needs-specific interventions refers to interventions that occur in the primary setting, either to directly provide services or to refer patients to other service providers, and they are grouped under subcategories for medical-legal partnerships; work, employment and welfare rights; food insecurity; and housing. Finally, the section on service users and service providers explores their respective perceptions of both facilitators and barriers to such interventions in the primary care setting.

\section{Screening tools and screening tool evaluations}

Social and economic needs screening tools for use in primary care have proliferated in the past two decades [48]. Screening alone cannot address unmet social and economic needs, but it is key to understanding the patient in both social and medical dimensions [70]. Screening tools can range from one question [71, 72] to multi-dimensional, detailed questionnaires $[73,74]$.

Screening toolkits have been designed for multiple delivery modes. They can be completed by the patient by themselves or in concert with a clinical or nonclinical staff member before or during the encounter [75]. There are paper-based and digital formats for many screening tools (Table 1). There are proprietary tools designed by the primary care practices that use them, ready-made tools from national organizations, or externally sourced from other organizations such as community legal practices. With a large number of tools available, it can be feasible to adapt existing tools to local need, rather than reinventing the wheel and customization is the norm $[26,76,77]$.

Among the evaluations and critiques of social needs screening tools, Gottlieb et al's 2016 randomized controlled trial (RCT) was the first to show that inperson navigation for social needs is associated with families reporting decreased social needs, and significantly improved caregiver-reported child health [87]. However, the accuracy of screening tools to assess social needs is largely unevaluated [88], with WE CARE and Kaiser Permanente's Your Current Life Situation notable exceptions $[86,89]$.
Complexity is not necessarily an advantage, particularly if the tool is designed for implementation by the health care provider during a patient encounter [78]. In a pilot study of a one-question poverty screening tool, the question:-"Do you ever have difficulty making ends meet at the end of the month"-had 98\% specificity and $68 \%$ sensitivity in predicting a patient's poverty [90]. Similarly, patients in a Virginia general internal medicine and emergency departments completed a 60-s survey to identify their unmet social needs, and the survey was effective in identifying the three most pressing unmet needs of the community the hospital serves [91].

In the studies focusing on food insecurity there was a definite tilt away from in-person screening, but for broader social needs screens, the findings from the literature were more mixed. How information is elicited can affect the screening outcome. On one hand, unstructured data collection can help reveal patients' more complex needs. On the other, bias and stigmatizing selection of patients for screening may reduce the tool's efficacy for detection of unmet social needs [92-94]. Other studies have demonstrated the acceptability of screening tools to patients $[81,95]$. These are explored below under service user perceptions.

\section{Economic needs-specific interventions Medical-legal partnerships}

Medical-legal partnerships are a response to the clear association between health and socioeconomic risks that are amenable to legal interventions [96]. Through a collaborative intervention they typically embed civil legal aid professionals in the clinical setting [97]. Clients' common presenting issues include problems with housing (including energy security), and income [96, 98, 99]. In the selected literature, almost all of the medical-legal partnerships are in the US. Outside the US, similar partnerships have been established in Canada [100, 101]. Given their mandate to provide primary care services in underserved areas, it is no surprise that $\mathrm{CHCs}$ are a natural home for health justice interventions and are where the number of medical-legal partnership services is growing the fastest [102-104]. Such services have a proven track record of helping clients obtain access to external food and income supports, claim unpaid welfare benefits, and prevent shut-offs of utilities $[96,99,105]$.

\section{Income, employment and welfare rights}

Food insecurity, insecure and substandard housing and poverty-related legal issues are the expression of a more fundamental problem of income inadequacy. With that in mind, income is not as common a screening question as might be expected [106]. However, income issues are seen by welfare rights service providers as a good fit for 


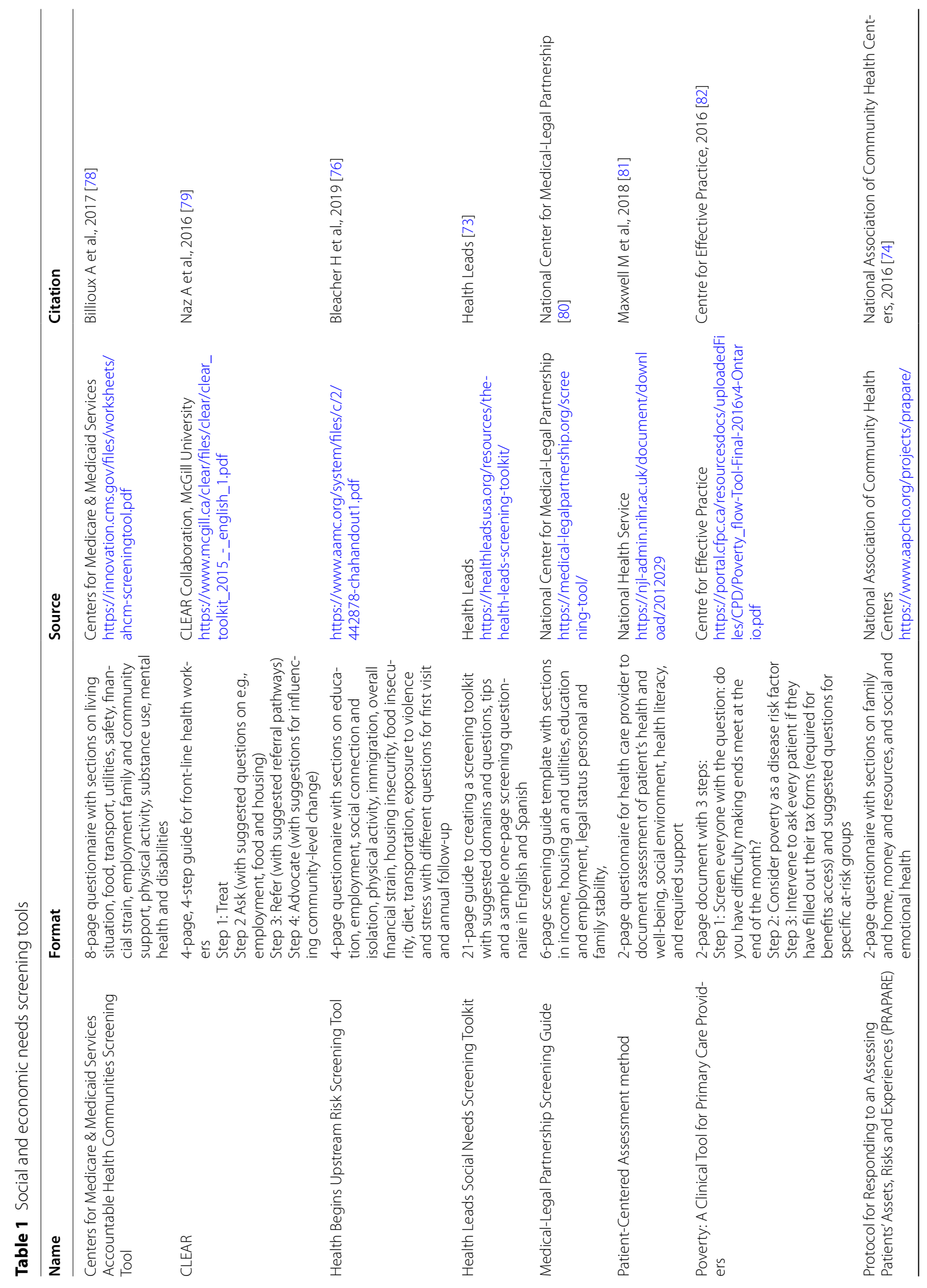




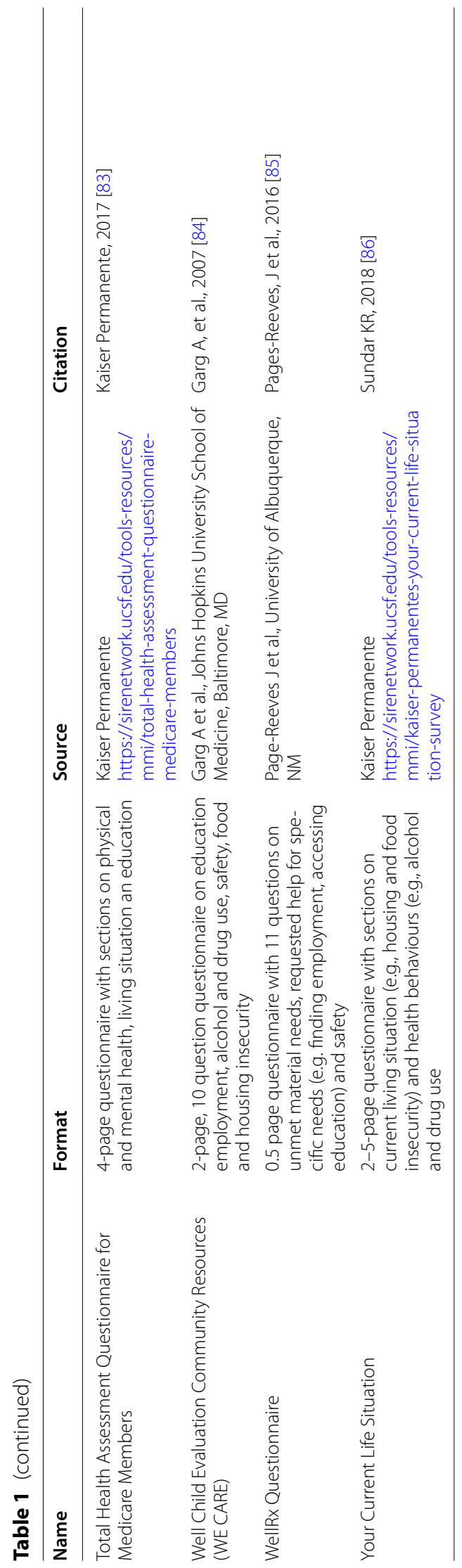


their skill set and is often flagged as a presenting issue $[96,105,107-109]$.

Studies of welfare rights services in primary care in the UK in the early 2000s reported increases in income for service users, as well as better self-reported mental and emotional health (although with only modest health improvements) [32, 110-116]. However, there is little evidence to date on the health impact of such interventions $[117,118]$. At the forefront of this work in Canada is the St Michael's Hospital Academic Family Health Team Social Determinants of Health Committee, which since 2013 has introduced numerous anti-poverty interventions, including socio-demographic screening and data collection, an income security health promotion service, a medical-legal partnership, a decent work initiative and a child literacy programme. Since 2013, the hospital's Income Security Health Promotion service has assisted clients to improve their income and reduce expenses, but the papers reviewed did not reveal and evidence of measurable health impact [119-122]. Similar to their US counterparts, Canadian CHCs have a built-in mandate to address the upstream determinants of health [123]. A recent social prescribing pilot run across $11 \mathrm{CHCs}$ in Ontario, which included financial needs interventions, to some extent formalized what $\mathrm{CHCs}$ are already doing in their respective communities [124-126].

In the UK, within its broad mandate of social prescribing (whereby the direction that the service takes is tailored to the needs identified by the client) the Bromley by Bow model includes welfare rights and employment support [127]. In 2016, the social prescribing service offered by Bromley by Bow was rolled out across the London Borough of Tower Hamlets via 37 general practitioner practices [128]. In Scotland, The Deep End Advice Worker Project-one of a collection of Deep End Project activities of General Practitioners at the Deep End, serving the 100 most deprived communities in Scotland-brings advice services to two of the most socially deprived areas of Glasgow [129, 130]. Noteworthy is that the model is one of assimilation, to embed the advice worker into the primary care practice, rather than colocate services. Embedding the advice worker into the care team enables the service to increase its reach and benefit from the established relationship of trust between a patient and doctor, and between the advice workers and primary care physicians [131, 132]. As for employment, income interventions targeting employment are scarce and mainly focused on patients with mental illness [133].

\section{Food insecurity}

Food insecurity has been associated with adverse health outcomes [134, 135]. Leonard et al's examination of overlapping clusters of food insecurity and poor health are suggestive of "shared causal mechanisms", and the American Academy of Pediatrics (AAP) recommends screening for food insecurity [136-138]. Notably, food insecurity was one of the most common topics in the literature under review, with numerous dedicated screening tools, as well as frequent inclusion in wider screens, indicating that it may be seen as particularly amenable to intervention in the primary care setting [71, 137, 139-143]. It can present both challenges and opportunities for providers, including administration issues; a practice champion or advocate may be helpful in overcoming these challenges [144-146]. Although food insecurity screening may present an opportunity for further exploration of a patient's social needs when asked in person, eliciting the information via a paper or digital questionnaire captures more revealing answers, reflecting the stigma associated with being unable to provide food for oneself or one's family [137, 141, 145, 147-149].

A review of 29 peer-reviewed studies on food insecurity interventions either alone or in combination with other interventions identified three typical mechanisms: passive or active referrals to community and/or government agencies; vouchers for use at fresh produce outlets; and direct provision of food either by delivery or through an on-site food pantry [150]. It is, however, uncommon for studies to evaluate the outcome in terms of health or service utilization [151]. It is notable that food insecurity interventions are prevalent in the US and also in Canada. One explanation is that addressing food insecurity is in some ways a 'quick win': it is quick and easy to detect in screening and document, and can be directly addressed with referrals to food banks or even on-site food pantries. This is far more achievable in a primary care setting than tackling upstream causes, i.e., income insecurity, and is line with the proliferation of municipal-level food based interventions [152].

\section{Housing}

Lack of access to adequate housing is known to contribute to poor health [153, 154]. Housing, sometimes described as housing instability or homelessness, is frequently identified in the literature on screening and intervention for unmet social needs [155-160]. Housing security status is a common component of social needs screening tools $[49,69,72,89,98,161,162]$. Knowing that a patient is homeless or unstably housed can have an influence on clinical decision making [163-166]. Stabilizing housing is a key aim and outcome of inter-professional interventions and medical-legal partnership programmes [21, 96, 97, 107, 167-171].

An interesting aspect of health system interventions to address social needs is their involvement in creating affordable housing. Most interventions of this kind to 
date have been in the hospital setting rather than primary care, but they reflect a general growing awareness of the intertwined relationship between housing and health, and the merits of a Housing First approach [172-179]. It remains to be seen whether this interest in direct intervention in the form of affordable housing emerges in the primary care sector too.

\section{Service user and service provider perceptions of facilitators and barriers \\ Service users}

While studies of primary care providers report fearing that they will create unrealistic expectations for their patients, other studies have found that on the contrary, patients understand the limitations of what their doctors can do to address their social needs, but nevertheless appreciate their efforts to do so, feel cared-for and find screening for social needs acceptable [39, 147, 154, 180183]. However, this requires that broaching the subject of social needs be done with sensitivity to patients' feelings of stigma, and fear of being reported to social service agencies if, for example they disclose that they do not have enough food to feed their children [148, 183]. Some studies report that patients welcome in-person help, whilst others prefer screening and referral modalities that are not face-to-face which can help overcome barriers of stigma [148, 160, 184, 185]. Patients do not always want their primary care providers to act on the identified unmet social needs [162, 182].

\section{Service providers}

Social needs screening is valued by physicians, as a way to improve their understanding of their patients $[45,147$, $162,181,186]$. In the US, for CHCs, screening often formalizes what they are already doing [187-189]. However, even among motivated physicians, uptake of screening can be low, unless it is routine and/or mandatory [154, 190-192]. Successful implementation relies on staff buyin, training, integration into clinic workflows, and, for the best effect, a clinical champion [166, 193-196]. It requires the service provider to overcome ignorance about patients' lived reality of poverty, push past discomfort with asking potentially stigmatizing questions, and having the communications skills set to do so [94, 197, 198].

Whereas primary care has strong linkages with other parts of the health system, linkages with social services are weak, navigation is complex and can hinder primary care providers' efforts at referral [199]. Implementation of a social needs screening and assistance process can be challenging and resource-intensive [162, 197]. Facilitators include physical proximity, clear pathways for referral and a sense of mutual respect and shared aims, as well as practical considerations such as allocation of time away from clinical duties [196, 200].

A common theme in the literature is the key role played by a patient navigator. There are many terms to describe this connector role, including link worker, communitylinks practitioner, income security health promoter, family specialist, and care navigator [33, 53, 201-203]. The connector can also help bridge the gap between the norms and values of medical practitioners and the social services sector, improve physician satisfaction and help prevent burnout [154, 196, 204-210]. For the connector, common challenges include boundary setting and managing client expectations. Facilitators of success include lived experience of poverty, training and active buy-in from care providers [204, 211].

\section{Discussion}

By far the most numerous were papers on interventions in the US. Apart from the sheer size of the population and complexity of the country's health systems, several possible reasons for the preponderance of interventions emerged from the literature. Firstly, professional and government bodies including the American Academy of Pediatrics, and the American Academy of Family Physicians have participated in the call for physicians to address SDOH [212-214]. Both the National Association of Community Health Centers, and the Centers for Medicare and Medicaid Services have produced SDOH screening tools [49, 74, 78]. Secondly, there are readily identifiable suitable venues for SDOH interventions, including $\mathrm{CHCs}$ serving Medicaid recipients and the uninsured [170, 215-217]. Paediatric clinic settings, where children typically have regular check-ups together with a caregiver, have also been a key site for such interventions in the US [84, 89, 210, 218-220]. Thirdly, there are favourable funding mechanisms, financial imperatives and incentives. The metric of hospitalization cost savings-with broader positive similar findings- was used in several studies under review [167, 221-226]. Both Medicaid Managed Care Organizations (MMCOs) and Medicaid Accountable Care Organizations (ACOs) are actively involved in addressing SDOH [227-230].

Although social needs screening and interventions in primary care have really taken off in the past five to 10 years, they have a longer history than this trend would suggest. There were previous trends in this direction more than 20 years ago, such as the work done by family physicians in the UK to partner with welfare rights providers [108, 231]. Similarly in Canada, as early as 2001, the health sector was identified as a forum within which poverty could be addressed in Canada, and since then it 
has been the source of a series of interventions to address poverty among patients $[19,232]$.

Whatever the organizational structure, the ability to code and bill for non-medical services is key, and this is particularly apparent in the US [188]. In order to bill for services, health providers must typically input an International Statistical Classification of Diseases and Related Health Problems (ICD) code [233]. In the 10th ICD revision, there are 10 codes that relate to a patient's socioeconomic and psychosocial circumstances. However, the codes are somewhat of a blunt instrument, and the existence of a billing code does not in itself guarantee that a service related to it will be billable [234].

For any intervention to gain traction, either with policymakers for funding, or with those involved to be onside, it is essential to be able to make a case for it, and to make a case that is stronger than that for competing priorities. Producing quantitative data to support advocacy for interventions such as the ones discussed in this paper is challenging, because it is difficult to determine valid metrics. Measuring the health impact of SDOH is it itself difficult, let alone interventions to address them. With so many comingled and intersecting factors, it is hard to tease out the effect of one thing or another. Moreover, health improvements may manifest over a long time, making them difficult to measure within the time constraints of a pilot project for example.

Measuring success has proven challenging, and the literature to date suggests a number of tensions with regard to evaluation. Is patient self-reported well-being a good enough metric to define a programme's success? Are changes in health service utilization an adequate proxy for changes in health itself? Do health interventions have to yield benefits that are visible to the health sector to be deemed worthy of funding, or considered successful, or could the benefits accrue more tangentially, such as through decreased burden on the social welfare or justice system, or better educational outcomes? These are all issues that have yet to be explored in the literature.

While patient perspectives on income interventions have been examined, so far the emphasis has been on provider-led interventions. There is clearly more scope for more experimentation community-led interventions (such as those from the Bromley by Bow Centre in London), and more analysis of them.

\section{Strengths and limitations}

Whilst other studies have examined some of the themes covered in this scoping review, this is the first to take such a broad sweep of the landscape of interventions targeted towards patients' poverty, and to consider experiences across different countries, rather than focusing solely on the US. However, by only searching for publications in English, it may miss peer-reviewed studies and other grey literature published in other languages. The authors are aware, for example, of social needs screening tools that have been implemented in Japan, but this data could not be included under the inclusion criteria because it was only available in Japanese. As this is a scoping review, there is little examination of progamme efficacy and the sample for this descriptive review is non-random, comprised as it is of interventions that have attracted the interest of some academic researchers. This may create a biased view.

\section{Conclusion}

There is a wide range of tools and processes in use to identify patients experiencing poverty, and address their economic needs, ranging from those tailor-made to an individual health practice, or to address one specific dimension of $\mathrm{SDOH}$, to wide-ranging protocols that collect rich sociodemographic data. Primary care-based interventions that aim to address patients' income needs operate at all levels, from passive sociodemographic data collection upon patient registration, through referral to external services, to direct intervention in addressing patients' social insecurities such as providing on-site services including welfare system navigators and food pantries. The decision to undertake this work requires courage on the part of health care providers, because it can be difficult, time-consuming and complex. Success often relies on management buy-in and a practice champion. However, it is often appreciated, even when the scope of action available to health care providers is quite narrow. Economic needs interventions are typically found in settings with an identifiable patient population likely to have high unmet needs, with the number, scope and sophistication of programmes and interventions greatest in the US. Barriers to implementation include not just cost and time, but also navigating three different things: the complexity of social welfare system, the difficulty of billing for non-clinical services, and both patients' and care providers' emotions about what can be stigmatizing topics. Success is defined widely, from patient satisfaction, to health outcomes, but data on health outcomes is not widespread.

\section{Recommendations for future studies}

There are several areas for potential future research. Firstly, the health impact of primary care-based economic interventions is a nascent field of investigation, and more research is needed to better investigate this. Secondly, the natural progression from 
Table 2 MEDLINE search strategy and main results

\begin{tabular}{|c|c|c|c|c|c|}
\hline Search term & Search term & Search term & No of results & $\begin{array}{l}\text { Excluded: not } \\
\text { relevant/duplicates }\end{array}$ & $\begin{array}{l}\text { Included for } \\
\text { further screening }\end{array}$ \\
\hline \multirow[t]{11}{*}{ 'primary care' AND } & 'social determinants of health' & & 389 & 321 & 68 \\
\hline & 'social welfare' & & 119 & 112 & 17 \\
\hline & 'social needs' & & 160 & 136 & 24 \\
\hline & 'social prescribing' & & 44 & 13 & 31 \\
\hline & 'food insecurity' AND & 'screening' & 42 & 14 & 28 \\
\hline & 'social needs screening' & & 8 & 0 & 8 \\
\hline & 'welfare rights' & & 7 & 0 & 7 \\
\hline & 'housing insecurity' & & 6 & 6 & 0 \\
\hline & 'income security' & & 5 & 5 & 0 \\
\hline & 'social assistance' & & 17 & 17 & 0 \\
\hline & 'link worker' & & 12 & 12 & 0 \\
\hline \multirow{10}{*}{$\begin{array}{l}\text { 'primary care' OR 'family practice' } \\
\text { OR 'health cent }{ }^{* \prime} \text { AND }\end{array}$} & 'poverty' AND & 'screening' & 394 & 387 & 7 \\
\hline & 'poverty' AND & 'intervention' & 537 & 528 & 9 \\
\hline & 'social determinants of health' AND & 'screening' & 97 & 75 & 22 \\
\hline & 'social determinants of health' AND & 'intervention' & 86 & 86 & 0 \\
\hline & 'social needs' AND & 'intervention' & 38 & 36 & 2 \\
\hline & 'housing' AND & 'intervention' & 104 & 104 & 0 \\
\hline & 'food security' OR 'food insecurity' AND & 'intervention' & 387 & 387 & 0 \\
\hline & 'economic stability' & & 5 & 5 & 0 \\
\hline & 'employment' AND & 'intervention' & 212 & 212 & 0 \\
\hline & 'social needs' AND & 'screening' & 31 & 31 & 0 \\
\hline Total & & & 2700 & 2487 & 223 \\
\hline
\end{tabular}

individual-focused interventions, to those whereby the health care system engage at the community level to address upstream determinants such as lack of affordable housing and other infrastructural inadequacies, will be an interesting field of study [20]. Thirdly, the impact of COVID-19 on economic needs interventions in primary care, including the impact of remote service delivery modalities, is worthy of investigation.

\section{Appendix}

\section{Search strategy}

The following the search strategy for the MEDLINE database

As per the iterative nature of the scoping review methodology, searches change in order to reflect emerging insights. Accordingly, the search strategy presented here represents the most fruitful searches.

A search for published literature was performed by one of the authors (JP) on August 7th and 8th 2020 on MEDLINE (via OVID) The search was limited to English language publications, and to studies on human and not animal subjects, published between January 12,000 and the date of the search (i.e., August 7th or 8th 2020).
Key word searches comprised a combination of social and health key words. MEDLINE searches were conducted iteratively, using Boolean operators, starting with 'primary care' AND 'social determinants of health'. Subsequent searches took the first term and paired it instead with a number of terms identified through emerging analysis or from my previous research in this area: food insecurity, housing insecurity, income security, social needs, social needs screening, social assistance, social welfare, social prescribing, welfare rights, and link worker.

As the search progressed, the first search term was also expanded to 'primary care OR family practice OR health cent"' to capture literature that may only use these synonyms for primary care. Pairing 'primary care OR family practice OR health cent"' with 'poverty' and 'screening' or 'intervention' yielded hundreds of results (394 for screening 537 for intervention) but few (16 in total) studies that were relevant and had not already been captured.

As the iterative search process progressed, searches yielded many results, there were very few of relevance that had not already been captured, indicating that the searches initially conducted were successful in capturing most of the potentially relevant studies. The below Table 2 presents the most fruitful searches. 


\section{Acknowledgements \\ Not applicable.}

\section{Authors' contributions}

All authors contributed to the conception and design of the work. JP was solely responsible for the data generation and analysis. JP drafted the work and JD, MV and MG substantively revised it. All authors read and approved the final manuscript.

\section{Funding}

Jane Parry's doctoral work is supported by a Trillium graduate scholarship from the Government of Ontario.

\section{Availability of data and materials}

The datasets used and/or analysed during the current study are available from the corresponding author on reasonable request.

\section{Declarations}

\section{Ethics approval and consent to participate}

Not applicable.

\section{Consent for publication}

Not applicable.

\section{Competing interests}

The authors declare that they have no competing interests.

\section{Author details}

${ }^{1}$ Department of Health, Aging and Society, McMaster University, 1280 Main St West, Hamilton, ON L8S 4L8, Canada. ${ }^{2}$ Department of Family Medicine, McMaster University, 1280 Main St West, Hamilton, ON L8S 4L8, Canada.

Received: 3 June 2021 Accepted: 5 September 2021

Published online: 07 October 2021

\section{References}

1. World Health Organization. Social determinants of health. Available from: https://www.who.int/social_determinants/en/. Accessed 17 Sept 2021.

2. Key Health Inequalities in Canada A National Portrait. Public Health Agency of Canada; 2018

3. Benzeval MBL, Campbell M, Egan M, Lorenc T, Petticrew M, Popham F. How does money influence health? York: Joseph Rowntree Foundation; 2014

4. Department of Health and Social Security. Inequalities in Health: Report of a Research Working Group. London: Department of Health and Social Security; 1980.

5. Marmot M. The status syndrome: how your social standing affects your health and life expectancy. London: Bloomsbury; 2004.

6. Chung RY-N, Chung GK-K, Gordon D, Wong SY-S, Chan D, Lau MK-W, et al. Deprivation is associated with worse physical and mental health beyond income poverty: a population-based household survey among Chinese adults. Qual Life Res. 2018;27(8):2127-35.

7. Haushofer J, Fehr E. On the psychology of poverty. Science. 2014;344(6186):862-7.

8. Raphael D, Macdonald J, Colman R, Labonte R, Hayward K, Torgerson R. Researching income and income distribution as determinants of health in Canada: gaps between theoretical knowledge, research practice, and policy implementation. Health Policy. 2005;72(2):217-32.

9. Lustig DC, Strauser DR. Causal relationships between poverty and disability. Rehabil Couns Bull. 2007;50(4):194-202.

10. Willson A, Erfani A. Socioeconomic history \& preventable disease: a comparative analysis of fundamental cause theory. London: Conference on Health Over the Life Course; University of Western Ontario; 2009.
11. Bushnik T, Tjepkema M, Martel L. Socioeconomic disparities in life and health expectancy among the household population in Canada. Health Rep. 2020;31(1):3-14.

12. Finkelstein M. Relationship between income and mortality in a Canadian family practice cohort. Can Fam Physician. 2018;64(4):e181-e9.

13. Lightman EMA, Wilson B. Poverty is making us sick: a comprehensive survey of income and health in Canada. Toronto: Wellesley Institute; 2008.

14. Forget EL. The town with no poverty: the health effects of a Canadian guaranteed annual income field experiment. Can Public Policy. 2011;37(3):283-305.

15. Kaufman A. Theory vs practice: should primary care practice take on social determinants of health now? Yes. Ann Fam Med. 2016;14(2):100-1.

16. Solberg LI. Theory vs practice: should primary care practice take on social determinants of health now? No. Ann Fam Med. 2016;14(2):102-3.

17. Runyan CN. Assessing social determinants of health in primary care: liability or opportunity? Fam Syst Health. 2018;36(4):550-2.

18. Paula Braveman PLGL, Francis D, Arkin E, Acker J. What can the health care sector do to advance health equity? Princeton: Robert Wood Johnson Foundation; 2019.

19. Williamson DL. The role of the health sector in addressing poverty. Can J Public Health. 2001;92(3):178-83.

20. Onie R, Lavizzo-Mourey R, Lee T, Marks J, Perla R. Integrating social needs into health care: a twenty-year case study of adaptation and diffusion. Health Aff. 2018;37(2):240-7

21. Taylor LA, Tan AX, Coyle CE, Ndumele C, Rogan E, Canavan M, et al. Leveraging the social determinants of health: what works? PLoS One. 2016:11(8):e0160217.

22. Starfield B. Is primary care essential? Lancet. 1994;344(8930):1129-33.

23. Riley M, Laurie AR, Plegue MA, Richarson CR. The adolescent "expanded medical home": school-based health centers partner with a primary care clinic to improve population health and mitigate social determinants of health. J Am Board Fam Med. 2016;29(3):339-47.

24. Davis TK, Montford CR, Read C. Interdisciplinary teamwork in a schoolbased health center. Nurs Clin North Am. 2005:40(4):699-+

25. Primary health care. World Health Organization. Available from: https:// www.who.int/news-room/fact-sheets/detail/primary-health-care Accessed 17 Sept 2021

26. LaForge K, Gold R, Cottrell E, Bunce AE, Proser M, Hollombe C, et al. How 6 organizations developed tools and processes for social determinants of health screening in primary care: an overview. J Ambulatory Care Manage. 2018;41(1):2-14

27. Health Leads. Screening for social determinants of health among children and families living in poverty: a guide for clinicians. Available from: https://healthleadsusa.org/resources/screening-for-social-determinan ts-of-health-among-children-and-families-living-in-poverty-a-guidefor-clinicians/. Accessed 17 Sept 2021

28. Grus I, Bunce A, Davis J, Dambrun K, Cottrell E, Gold R. Initiating and implementing social determinants of health data collection in community health centers. Popul Health Manag. 2020;02:02.

29. O'Gurek DT, Henke C. A practical approach to screening for social determinants of health. Fam Pract Manag. 2018:25(3):7-12.

30. Silverstein M, Conroy K, Sandel M. Screening for social determinants of health in pediatric primary care. Pediatr Ann. 2008:37(11):740-6.

31. Pescheny J, Randhawa G, Pappas Y. Patient uptake and adherence to social prescribing: a qualitative study. BJGP Open. 2018;2(3):bjgpopen18X101598.

32. Abbott S. Prescribing welfare benefits advice in primary care: is it a health intervention, and if so, what sort? J Public Health Med. 2002;24(4):307-12.

33. Jones MK, Bloch G, Pinto AD. A novel income security intervention to address poverty in a primary care setting: a retrospective chart review. BMJ Open. 2017:7(8):e014270.

34. Klass P, Dreyer BP, Mendelsohn AL. Reach out and read: literacy promotion in pediatric primary care. Adv Pediatr. 2009;56(1):11-27.

35. Vasan A, Solomon BS. Use of colocated multidisciplinary services to address family psychosocial needs at an urban pediatric primary care clinic. Clin Pediatr (Phila). 2015:54(1):25-32.

36. Goldfarb S. Take two aspirin and call me by my pronouns. Wall Street Journal. 2019. Available from: https://www.wsj.com/articles/ 
take-two-aspirin-and-call-me-by-my-pronouns-11568325291. Accessed 17 Sept 2021.

37. Tudor HJ. The inverse care law. Lancet. 1971;297(7696):405-12.

38. Watt G. The inverse care law today. Lancet. 2002;360(9328):252-4

39. Garg A, Boynton-Jarrett R, Dworkin PH. Avoiding the unintended consequences of screening for social determinants of health. JAMA. 2016;316(8):813-4.

40. Goldstein D, Holmes J. Health care's blind side. Princeton: Robert Wood Johnson Foundation; 2011.

41. Boozary A, Laupacis A. The mirage of universality: Canada's failure to act on social policy and health care. Can Med Assoc J. 2020;192(5):E105-E6.

42. De Marchis EH, Alderwick H, Gottlieb LM. Do patients want help addressing social risks? J Am Board Fam Med. 2020;33(2):170-5.

43. Garg A, Jack B, Zuckerman B. Addressing the social determinants of health within the patient-centered medical home: lessons from pediatrics. JAMA. 2013;309(19):2001-2.

44. Andermann A. Taking action on the social determinants of health in clinical practice: a framework for health professionals. Can Med Assoc J. 2016;188(17-18):E474-E83.

45. College of Family Physicians of Canada. ePanel report: social determinants of health. Mississauga: College of Family Physicians of Canada; 2016.

46. Fichtenberg CM, Alley DE, Mistry KB. Improving social needs intervention research: key questions for advancing the field. Am J Prev Med. 2019;57(6):S47-54.

47. Cannuscio C, Meisel ZF, Feuerstein-Simon R. Social justice is the foundation of healthcare - and medical education I Opinion. Philadelphia: Philadelphia Inquirer; 2019. Sect. Opinion.

48. Andermann A. Screening for social determinants of health in clinical care: moving from the margins to the mainstream. Public Health Rev. 2018;39(1):19.

49. Fraze TK, Brewster AL, Lewis VA, Beidler LB, Murray GF, Colla CH. Prevalence of screening for food insecurity, housing instability, utility needs, transportation needs, and interpersonal violence by US physician practices and hospitals. JAMA Netw. 2019;2(9):e1911514.

50. Boch S, Keedy H, Chavez L, Dolce M, Chisolm DJ. An integrative review of social determinants of health screenings used in primary care settings. J Health Care Poor Underserved. 2020;31(2):603-22.

51. Carter N, Valaitis RK, Lam A, Feather J, Nicholl J, Cleghorn L. Navigation delivery models and roles of navigators in primary care: a scoping literature review. BMC Health Serv Res. 2018;18(1):96.

52. Pescheny JV, Pappas Y, Randhawa G. Facilitators and barriers of implementing and delivering social prescribing services: a systematic review. BMC Health Serv Res. 2018;18(1):86.

53. Tierney S, Wong G, Roberts N, Boylan AM, Park S, Abrams R, et al. Supporting social prescribing in primary care by linking people to local assets: a realist review. BMC Med. 2020;18(1):49.

54. Lucyk K, McLaren L. Taking stock of the social determinants of health: a scoping review. PLoS One. 2017;12(5):e0177306.

55. Gottlieb LM, Wing H, Adler NE. A systematic review of interventions on patients' social and economic needs. Am J Prev Med. 2017;53(5):719-29.

56. Peters MDJ, Godfrey CM, Khalil H, Mclnerney P, Parker D, Soares CB. Guidance for conducting systematic scoping reviews. Int J Evid Based Healthc. 2015;13(3):141-6.

57. Levac D, Colquhoun H, O'Brien KK. Scoping studies: advancing the methodology. Implement Sci. 2010;5(1):69.

58. The Joanna Briggs Institute. Joanna Briggs Institute Reviewers' Manual: 2015 edition/supplement. Adelaide: The Joanna Briggs Institute; 2015.

59. Colquhoun HL, Levac D, O'Brien KK, Straus S, Tricco AC, Perrier L, et al. Scoping reviews: time for clarity in definition, methods, and reporting. J Clin Epidemiol. 2014;67(12):1291-4.

60. Peterson J, Pearce PF, Ferguson LA, Langford CA. Understanding scoping reviews: definition, purpose, and process. J Am Assoc Nurse Pract. 2017;29(1):12-6.

61. Arksey H, O'Malley L. Scoping studies: towards a methodological framework. Int J Soc Res Methodol. 2005:8(1):19-32.

62. Tricco AC, Lillie E, Zarin W, O'Brien KK, Colquhoun H, Levac D, et al. PRISMA extension for scoping reviews (PRISMA-SCR): checklist and explanation. Ann Intern Med. 2018;169(7):467-73.

63. Hsieh H-F, Shannon SE. Three approaches to qualitative content analysis. Qual Health Res. 2005;15(9):1277-88.
64. Downe-Wamboldt B. Content analysis: method, applications, and issues. Health Care Women Int. 1992;13:313-21.

65. Lombardi BM, Zerden LS, Richman EL. Where are social workers co-located with primary care physicians? Soc Work Health Care. 2019;58(9):885-98.

66. Kangovi SMN, Grande D, Long JA, Asch DA. Evidence-based community health worker program addresses unmet social needs and generates positive return on investment. Health Aff. 2020;39(2):207-13.

67. Davis-Hall M. The Bromley by Bow Centre: harnessing the power of community. Br J Gen Pract. 2018;68(672):333.

68. Krist AH, O'Loughlin K, Woolf SH, Sabo RT, Hinesley J, Kuzel AJ, et al. Enhanced care planning and clinical-community linkages versus usual care to address basic needs of patients with multiple chronic conditions: a clinician-level randomized controlled trial. Trials. 2020;21(1):517.

69. Zhu E, Ahluwalia JS, Laws MB. An evaluation of connect for health: a social referral program in RI. R I Med. 2020;103(5):65-9.

70. Perrin EC. Screening for both child behavior and social determinants of health in pediatric primary care: commentary. J Dev Behav Pediatr. 2019:40(6):470-1.

71. Kleinman RE, Murphy JM, Wieneke KM, Desmond MS, Schiff A, Gapinski JA. Use of a single-question screening tool to detect hunger in families attending a neighborhood health center. Ambul Pediatr. 2007;7(4):278-84.

72. Brcic VEC, Kaczorowski J. Development of a tool to identify poverty in a family practice setting: a pilot study. Int J Family Med. 2011.

73. Health Leads. Social needs screening toolkit. Boston: Health Leads; 2016.

74. National Association of Community Health Centers. Protocol for Responding to and Assessing Patient Assets, Risks, and Experiences (PRAPARE). Available from: https://www.nachc.org/research-anddata/prapare/. Accessed 17 Sept 2021.

75. Byhoff E, Cohen AJ, Hamati MC, Tatko J, Davis MM, Tipirneni R. Screening for social determinants of health in Michigan health centers. J Am Board Fam Med. 2017;30(4):418-27.

76. Bleacher H, Lyon C, Mims L, Cebuhar K, Begum A. The feasibility of screening for social determinants of health: seven lessons learned. Fam Pract Manag. 2019;26(5):13-9.

77. Burke G, Ramos-Callan K, Shearer C. Complex construction: a framework for building clinical-community partnerships to address social determinants of health. New York: United Hospital Fund; 2019.

78. Billioux A, Verlander K, Anthony S, Alley D. In: Medicine NAo, editor. Standardized screening for health-related social needs in clinical settings the accountable health communities screening tool; 2017.

79. Naz A, Rosenberg E, Andersson N, Labonté R, Andermann A. Health workers who ask about social determinants of health are more likely to report helping patients: mixed-methods study. Can Fam Physician. 2016;62(11):e684-e93.

80. New MLP legal needs screening tool available for download. Washington, DC: National Center for Medical-Legal Partnership; 2015. Available from: https://medical-legalpartnership.org/screening-tool/. Accessed 17 Sept 2021

81. Maxwell M, Hibberd C, Aitchison P, Calveley E, Pratt R, Dougall N, et al. The Patient Centred Assessment Method for improving nurse-led biopsychosocial assessment of patients with long-term conditions: a feasibility RCT. NIHR J Lib. 2018;1:1.

82. Poverty: a clinical tool for primary care providers. Mississauga: Centre for Effective Practice; 2016. Available from: https://cep.health/clini cal-products/poverty-a-clinical-tool-for-primary-care-providers/. Accessed 17 Sept 2021

83. Total health assessment questionnaire for medicare members. Kaiser Foundation Health Plan, Inc; 2013. Available from: https://siren etwork.ucsf.edu/tools-resources/resources/total-health-assessmentquestionnaire-medicare-members. Accessed 17 Sept 2021.

84. Garg A, Butz AM, Dworkin PH, Lewis RA, Thompson RE, Serwint JR. Improving the management of family psychosocial problems at low-income children's well-child care visits: the WE CARE project. Pediatrics. 2007;120(3):547-58

85. Page-Reeves J, Kaufman W, Bleecker M, Norris J, McCalmont K, lanakieva $\mathrm{V}$, et al. Addressing social determinants of health in a clinic 
setting: the WellRx pilot in Albuquerque, New Mexico. J Am Board Fam Med. 2016;29(3):414-8.

86. Sundar KR. Universal screening for social needs in a primary care clinic a quality improvement approach using the your current life situation survey. Perm. 2018;22:18-089.

87. Gottlieb L, Hessler D, Long D, Amaya A, Adler N. A randomized trial on screening for social determinants of health: the iScreen study. Pediatrics. 2014;134(6):E1611-E8.

88. Sokol R, Austin A, Chandler C, Byrum E, Bousquette J, Lancaster C, et al. Screening children for social determinants of health: a systematic review. Pediatrics. 2019;144(4):e20191622.

89. Garg A, Toy S, Tripodis Y, Silverstein M, Freeman E. Addressing social determinants of health at well child care visits: a cluster RCT. Pediatrics. 2015;135(2):e296-304.

90. Brcic V, Eberdt C, Kaczorowski J. Development of a tool to identify poverty in a family practice setting: a pilot study. Int J Family Med. 2011;2011:812182.

91. Reves SR, O'Neal JP, Gonzalez MM, McHenry C, Favour M, Etz RS. A 60-second survey to identify patients' unmet social needs. Ann Fam Med. 2019:17(3):274.

92. Vest JR, Grannis SJ, Haut DP, Halverson PK, Menachemi N. Using structured and unstructured data to identify patients' need for services that address the social determinants of health. Int J Med Inf. 2017;107:101-6.

93. Vest JR, Menachemi N, Grannis SJ, Ferrell JL, Kasthurirathne SN, Zhang Y, et al. Impact of risk stratification on referrals and uptake of wraparound services that address social determinants: a stepped wedged trial. Am J Prev Med. 2019;56(4):e125-e33.

94. Wallace AS, Luther B, Guo JW, Wang CY, Sisler S, Wong B. Implementing a social determinants screening and referral infrastructure during routine emergency department visits, Utah, 2017-2018. Prev Chronic Dis. 2020;17:E45.

95. Selvaraj K, Ruiz MJ, Aschkenasy J, Chang JD, Heard A, Minier M, et al. Screening for toxic stress risk factors at well-child visits: the addressing social key questions for health study. J Pediatr. 2019;205:244-9.e4.

96. Klein MD, Beck AF, Henize AW, Parrish DS, Fink EE, Kahn RS. Doctors and lawyers collaborating to HeLP children--outcomes from a successful partnership between professions. J Health Care Poor Underserved. 2013:24(3):1063-73.

97. Regenstein M, Trott J, Williamson A, Theiss J. Addressing social determinants of health through medical-legal partnerships. Health Aff. 2018;37(3):378-85.

98. DeJong NA, Wood CT, Morreale MC, Ellis C, Davis D, Fernandez J, et al. Identifying social determinants of health and legal needs for children with special health care needs. Clin Pediatr (Phila). 2016;55(3):272-7.

99. Taylor DR, Bernstein BA, Carroll E, Oquendo E, Peyton L, Pachter LM. Keeping the heat on for children's health: a successful medical-legal partnership initiative to prevent utility shutoffs in vulnerable children. J Health Care Poor Underserved. 2015;26(3):676-85.

100. Drozdzal G, Shoucri R, Macdonald J, Radford K, Pinto AD, Persaud N. Integrating legal services with primary care. Health Justice Prog. 2019:65(4):246-8.

101. Legal health check-up: Legal Health Check-Up. Available from: https:// legalhealthcheckup.ca/en/. Accessed 17 Sept 2021

102. National Center for Medical-Legal Partnership. Washington, DC: National Center Initiatives. Available from: https://medical-legalpartn ership.org/impact/initiatives/. Accessed 17 Sept 2021

103. Marple K. Using the law to inform empowered patient care in Austin. Washington, DC: National Center for Medical-Legal Partnership; 2018.

104. Lawton R, Whitehead M, Henize A, Fink E, Salamon M, Kahn R, et al. Medical-legal-psychology partnerships - innovation in addressing social determinants of health in pediatric primary care. Acad Pediatr. 2020;19:19.

105. Weintraub DMD, Rodgers MAJD, Botcheva LP, Loeb ABA, Knight RJD, Ortega KMA, et al. Pilot study of medical-legal partnership to address social and legal needs of patients. J Health Care Poor Underserved. 2010:21(2):157-68.

106. Social Interventions Research \& Evaluation Network. Social need screening tools comparison table. Available from: https://sirenetwork. ucsfedu/tools-resources/resources/screening-tools-comparison-tables. Accessed 17 Sept 2021.
107. Tobin Tyler E. Medical-legal partnership in primary care: moving upstream in the clinic. Am J Lifestyle Med. 2019;13(3):282-91.

108. Greasley P, Small N. Establishing a welfare advice service in family practices: views of advice workers and primary care staff. Fam Pract. 2005;22(5):513-9.

109. Hassan A, Scherer EA, Pikcilingis A, Krull E, McNickles L, Marmon G, et al. Improving social determinants of health: effectiveness of a web-based intervention. Am J Prev Med. 2015;49(6):822-31.

110. Coppel DH, Packham CJ, Varnam MA. Providing welfare rights advice in primary care. Public Health. 1999;113(3):131-5.

111. Hoskins R, Tobin J, McMaster K, Quinn T. Roll-out of a nurse-led welfare benefits screening service throughout the largest local health care co-operative in Glasgow: an evaluation study. Public Health. 2005;119(10):853-61.

112. Hoskins RA, Smith LN. Nurse-led welfare benefits screening in a general practice located in a deprived area. Public Health. 2002;116(4):214-20.

113. Moffatt S, Mackintosh J, White M, Howel D, Sandell A. The acceptability and impact of a randomised controlled trial of welfare rights advice accessed via primary health care: qualitative study. BMC Public Health. 2006:6:163.

114. Toeg D, Mercer L, lliffe S, Lenihan P. Proactive, targeted benefits advice for older people in general practice: a feasibility study. Health Soc Care Community. 2003;11(2):124-8.

115. Greasley P, Small N. Providing welfare advice in general practice: referrals, issues and outcomes. Health Soc Care Community. 2005;13(3):249-58.

116. Powell JE, Langley C, Kirwan J, Gubbay D, Memel D, Pollock J, et al. Welfare rights services for people disabled with arthritis integrated in primary care and hospital settings: set-up costs and monetary benefits. Rheumatology (Oxford). 2004;43(9):1167-72.

117. Abbott S, Hobby L, Cotter S. What is the impact on individual health of services in general practice settings which offer welfare benefits advice? Health Soc Care Community. 2005;14(1):1-8.

118. Mackintosh J, White M, Howel D, ChadwickT, Moffatt S, Deverill M, et al. Randomised controlled trial of welfare rights advice accessed via primary health care: pilot study [ISRCTN61522618]. BMC Public Health. 2006;6(1):162

119. Parry J. Practising equity-focused health care. How St. Michael's Hospital Academic Family Health Team works to address the social determinants of health. St. Michael's Academic Family Health Team. 2020.

120. Unity Health Toronto. Social determinants of health. Available from: https://unityhealth.to/social-determinants-of-health/. Accessed 17 Sept 2021.

121. Pinto AD, Glattstein-Young G, Mohamed A, Bloch G, Leung F-H, Glazier RH. Building a foundation to reduce health inequities: routine collection of sociodemographic data in primary care. J Am Board Fam Med. 2016;29(3):348-55.

122. Pinto $A D$, Bloch $\mathrm{G}$. Framework for building primary care capacity to address the social determinants of health. Can Fam Physician. 2017;63(11):e476-e82.

123. Collins PA, Resendes SJ, Dunn JR. The untold story: examining Ontario's Community Health Centres' initiatives to address upstream determinants of health. Healthc Policy. 2014:10(1):14-29.

124. Rx Community: social prescribing. Alliance for Healthier Communities. Available from: https://www.allianceon.org/Social-Prescribing. Accessed 17 Sept 2021.

125. Mulligan K. Director of Policy and Communications, Alliance for Healthier Communities. Personal communication. 30th September 2019.

126. Mulligan K, Hsiung S, Bhatti S, Rehel J, Rayner J. Social prescribing in Ontario final report. Toronto: Alliance for Healthier Communities; 2020.

127. Bromley by Bow Centre. Supporting you to find work. London: 2020. Available from: https://www.bbbc.org.uk/services/find-work/. Accessed 17 Sept 2021.

128. Cannon L, Ferguson K. Key findings from the tower hamlets social prescribing survey 2017. London: Tower Hamlets Together; 2018.

129. Deep End Project. Deep end manifesto 2017. Glasgow: Deep End Project; 2017.

130. Watt GC. The exceptional potential of general practice. Boca Raton: CRC Press: 2019 
131. Sinclair J. Policy in practice. London: Policy in Practice; 2018. Available from: http://policyinpractice.co.uk/glasgows-deep-end-advice-workerproject-improving-accessibility-of-advice-services/

132. Sinclair J. The deep end advice worker project: embedding an advice worker in general practice settings. Glasgow: Glasgow Centre for Population Health; 2017.

133. Pinto AD, Hassen N, Craig-Neil A. Employment interventions in health settings: a systematic review and synthesis. Ann Fam Med. 2018;16(5):447-60.

134. Seligman HK, Jacobs EA, López A, Tschann J, Fernandez A. Food insecurity and glycemic control among low-income patients with type 2 diabetes. Diabetes Care. 2012;35(2):233-8.

135. Bahadur K, Pai S, Thoby E, Petrova A. Frequency of food insecurity and associated health outcomes in pediatric patients at a federally qualified health center. J Community Health. 2018;43(5):896-900.

136. Leonard T, Hughes AE, Donegan C, Santillan A, Pruitt SL. Overlapping geographic clusters of food security and health: where do social determinants and health outcomes converge in the U.S? SSM Popul Health. 2018;5:160-70.

137. Adams E, Hargunani D, Hoffmann L, Blaschke G, Helm J, Koehler A. Screening for food insecurity in pediatric primary care: a clinic's positive implementation experiences. J Health Care Poor Underserved. 2017;28(1):24-9

138. Council on Community Pediatrics and Committee on Nutrition. Promoting food security for all children. Pediatrics. 2015;136(5):e1431-e8.

139. Robinson T, Bryan L, Johnson V, McFadden T, Lazarus S, Simon HK. Hunger: a missed opportunity for screening in the pediatric emergency department. Clin Pediatr (Phila). 2018;57(11):1318-25.

140. Beck AF, Henize AW, Kahn RS, Reiber KL, Young JJ, Klein MD. Forging a pediatric primary care-Community partnership to support food-insecure families. Pediatrics. 2014;134(2):E564-E71.

141. Cullen D, Woodford A, Fein J. Food for thought: a randomized trial of food insecurity screening in the emergency department. Acad Pediatr. 2019;19(6):646-51.

142. Makelarski JA, Abramsohn E, Benjamin JH, Du SX, Lindau ST. Diagnostic accuracy of two food insecurity screeners recommended for use in health care settings. Am J Public Health. 2017;107(11):1812-7.

143. Gattu RK, Paik G, Wang Y, Ray P, Lichenstein R, Black MM. The hunger vital sign identifies household food insecurity among children in emergency departments and primary care. Children (Basel). 2019;6(10):02.

144. Pooler JA, Hoffman VA, Karva FJ. Primary care providers' perspectives on screening older adult patients for food insecurity. J Aging Soc Policy. 2018;30(1):1-23

145. Knowles M, Khan S, Palakshappa D, Cahill R, Kruger E, Poserina BG, et al. Successes, challenges, and considerations for integrating referral into food insecurity screening in pediatric settings. J Health Care Poor Underserved. 2018;29(1):181-91.

146. Chiu S, Okafor M. Challenges and strategies in the implementation of a two-item food insecurity screening tool in primary care. Educ Prim Care. 2019;30(1):52-4.

147. Palakshappa D, Doupnik S, Vasan A, Khan S, Seifu L, Feudtner C, et al. Suburban families' experience with food insecurity screening in primary care practices. Pediatrics. 2017;140(1):e20170320.

148. Palakshappa D, Goodpasture M, Albertini L, Brown CL, Montez K, Skelton JA. Written versus verbal food insecurity screening in one primary care clinic. Acad Pediatr. 2020;20(2):203-7.

149. Barnidge E, LaBarge G, Krupsky K, Arthur J. Screening for food insecurity in pediatric clinical settings: opportunities and barriers. J Community Health. 2017:42(1):51-7.

150. De Marchis E, Fichtenberg C, Gottlieb L. Food insecurity interventions in health care settings: a review of the evidence. San Francisco: University of California, San Francisco Social Interventions Research \& Evaluation Network; 2020.

151. De Marchis EH, Torres JM, Benesch T, Fichtenberg C, Allen IE, Whitaker EM, et al. Interventions addressing food insecurity in health care settings: a systematic review. Ann Fam Med. 2019;17(5):436-47.

152. Collins P, Power E, Little M. Municipal-level responses to household food insecurity in Canada: a call for critical, evaluative research. Canad J Public Health. 2014;105(2):e138-e41.

153. Chung RYN, Chung GKK, Gordon D, et al. Housing affordability effects on physical and mental health: household survey in a population with the world's greatest housing affordability stress. J Epidemiol Community Health. 2020;74:164-72.

154. Popay J, Kowarzik U, Mallinson S, Mackian S, Barker J. Social problems, primary care and pathways to help and support: addressing health inequalities at the individual level. Part II: lay perspectives. J Epidemiol Community Health. 2007;61(11):972-7.

155. Driving innovative health care solutions for underserved populations. Association of American Medical Colleges; 2019. Available from: https:// www.aamc.org/news-insights/driving-innovative-health-care-solut ions-underserved-populations. Accessed 17 Sept 2021.

156. Better Health through housing. University of Illinois Health. Available from: https://hospital.uillinois.edu/about-ui-health/community-commi tment/better-health-through-housing. Accessed 17 Sept 2021.

157. Losonczy LI, Hsieh D, Wang M, Hahn C, Trivedi T, Rodriguez M, et al. The Highland Health Advocates: a preliminary evaluation of a novel programme addressing the social needs of emergency department patients. Emerg Med J. 2017;34(9):599-605.

158. McGuire J, Bikson K, Blue-Howells J. How many social workers are needed in primary care? A patient-based needs assessment example. Health Soc Work. 2005;30(4):305-13.

159. O'Brien KH. Social determinants of health: the how, who, and where screenings are occurring; a systematic review. Soc Work Health Care. 2019;58(8):719-45.

160. Oldfield BJ, Casey M, DeCew A, Morales SI, Olson DP. Screening for social determinants of health among children: patients' preferences for receiving information to meet social needs and a comparison of screening instruments. Popul Health Manag. 2020;25:25.

161. Higginbotham K, Davis Crutcher T, Karp SM. Screening for social determinants of health at well-child appointments: a quality improvement project. Nurs Clin N Am. 2019;54(1):141-8.

162. Tong ST, Liaw WR, Kashiri PL, Pecsok J, Rozman J, Bazemore AW, et al. Clinician experiences with screening for social needs in primary care. J Am Board Fam Med. 2018;31(3):351-63.

163. Chhabra M, Sorrentino AE, Cusack M, Dichter ME, Montgomery AE, True G. Screening for Housing instability: providers' reflections on addressing a social determinant of health. J Gen Intern Med. 2019;34(7):1213-9.

164. Coughlin SS, Mann P, Vernon M, Young L, Ayyala D, Sams R, et al. A logic framework for evaluating social determinants of health interventions in primary care. J Hosp Manag Health Policy. 2019;3:23.

165. Klein MD, Kahn RS, Baker RC, Fink EE, Parrish DS, White DC. Training in social determinants of health in primary care: does it change resident behavior? Acad Pediatr. 2011;11(5):387-93.

166. Patel M, Bathory E, Scholnick J, White-Davis T, Choi J, Braganza S. Resident documentation of social determinants of health: effects of a teaching tool in the outpatient setting. Clin Pediatr (Phila). 2018;57(4):451-6.

167. Bradley KJ, Wros P, Bookman N, Mathews LR, Voss H, Ostrogorsky TL, et al. The Interprofessional Care Access Network (I-CAN): achieving client health outcomes by addressing social determinants in the community. J Interprof Care. 2018:1-8.

168. Clark CR, Baril N, Kunicki M, Johnson N, Soukup J, Ferguson K, et al. Addressing social determinants of health to improve access to early breast cancer detection: results of the Boston REACH 2010 Breast and Cervical Cancer Coalition Women's Health Demonstration Project. J Women's Health (Larchmt). 2009;18(5):677-90.

169. Greasley P. Welfare advice in general practice: a resource for community nurses. Br J Community Nurs. 2005;10(8):368-72.

170. Kranz AM, Mahmud A, Agniel D, Damberg C, Timbie JW. Provision of social services and health care quality in US community health centers, 2017. Am J Public Health. 2020;110(4):567-73.

171. Sandel M, Hansen M, Kahn R, Lawton E, Paul E, Parker V, et al. Medicallegal partnerships: transforming primary care by addressing the legal needs of vulnerable populations. Health Aff. 2010;29(9):1697-705.

172. Parker D. Housing as an intervention on hospital use: access among chronically homeless persons with disabilities. J Urban Health. 2010;87(6):912-9.

173. Reynolds K, Allen EH, Fedorowicz M, Ovalle J. Affordable housing investment a guide for nonprofit hospitals and health systems. Washington, DC: Urban Institute; 2019.

174. Grant K. Toronto-based hospital network commits land to build affordable housing. Toronto: The Globe and Mail; 2019. 
175. Hawryluk M. Why hospitals are getting into the housing business. Kaiser Health News; 2019. Available from: https://khn.org/news/why-hospi tals-are-getting-into-the-housing-business/.

176. Flaccus G. 6 Portland health providers give $\$ 21.5 \mathrm{M}$ for homeless housing. Washington, D.C: US News \& World Report; 2016

177. Bartolone P. Hospitals step in to help house the homeless. will it make a difference? Menlo Park: California Healthline; 2017.

178. Hospital to housing. St Louis: St Patrick Center; 2019. Available from: http://stpatrickcenter.org/hospital-to-housing/. Accessed 17 Sept 2021

179. Cohn M. Bon Secours joins effort to build, sustain affordable housing projects. Baltimore: The Baltimore Sun; 2019.

180. De Marchis EH, Hessler D, Fichtenberg C, Adler N, Byhoff E, Cohen AJ, et al. Part I: a quantitative study of social risk screening acceptability in patients and caregivers. Am J Prev Med. 2019;57(6 Suppl 1):S25-37.

181. Orr CJ, Chauvenet C, Ozgun H, Pamanes-Duran C, Flower KB. Caregivers' experiences with food insecurity screening and impact of food insecurity resources. Clin Pediatr (Phila). 2019;58(14):1484-92.

182. Rogers AJ, Hamity C, Sharp AL, Jackson AH, Schickedanz AB. Patients' attitudes and perceptions regarding social needs screening and navigation: multi-site survey in a large integrated health system. J Gen Intern Med. 2020;35(5):1389-95.

183. Byhoff E, De Marchis EH, Hessler D, Fichtenberg C, Adler N, Cohen AJ, et al. Part II: a qualitative study of social risk screening acceptability in patients and caregivers. Am J Prev Med. 2019;57(6 Suppl 1):S38-46.

184. Jaganath D, Johnson K, Tschudy MM, Topel K, Stackhouse B, Solomon BS. Desirability of clinic-based financial services in urban pediatric primary care. J Pediatr. 2018:202:285-90.

185. Hsu C, Cruz S, Placzek H, Chapdelaine M, Levin S, Gutierrez F, et al. Patient perspectives on addressing social needs in primary care using a screening and resource referral intervention. J Gen Intern Med. 2020;35(2):481-9.

186. Swamy P, Monterrey AC, Wood MS, Troisi CL, Greeley CS. Caregiver and pediatric health care provider views on social needs identification. J Prim Care Community Health. 2020;11:2150132720923085.

187. Byhoff E, Garg A, Pellicer M, Diaz Y, Yoon GH, Charns MP, et al. Provider and staff feedback on screening for social and behavioral determinants of health for pediatric patients. J Am Board Fam Med. 2019:32(3):297-306

188. Lewis JH, Whelihan K, Navarro I, Boyle KR, Team SDHCSI. Community health center provider ability to identify, treat and account for the socia determinants of health: a card study. BMC Fam Pract. 2016;17:121.

189. Ward A, Asif A, Cattermole R, Chima J, Ebbatson T, Mahi I, et al. Social prescribing by students: the design and delivery of a social prescribing scheme by medical students in general practice. Educ Prim Care 2020;31(5):318-22

190. Purkey E, Bayoumi I, Coo H, Maier A, Pinto AD, Olomola B, et al. Exploratory study of "real world" implementation of a clinical poverty tool in diverse family medicine and pediatric care settings. Int J Equity Health. 2019;18(1):200.

191. Schickedanz A, Hamity C, Rogers A, Sharp AL, et al. Clinician experiences and attitudes regarding screening for social determinants of health in a large integrated health system. Med Care. 2019;57(Suppl 6 2):S197.

192. Babbel B, Mackenzie M, Hastings A, Watt G. How do general practitioners understand health inequalities and do their professional roles offer scope for mitigation? Constructions derived from the deep end of primary care. Crit Public Health. 2019;29(2):168-80.

193. Fiori K, Patel M, Sanderson D, Parsons A, Hodgson S, Scholnick J, et al. From policy statement to practice: integrating social needs screening and referral assistance with community health workers in an urban academic health center. J Prim Care Community Health. 2019:10:2150132719899207.

194. Gold R, Bunce A, Cowburn S, Dambrun K, Dearing M, Middendorf M, et al. Adoption of social determinants of health EHR tools by community health centers. Ann Fam Med. 2018;16(5):399-407.

195. Meyer D, Lerner E, Phillips A, Zumwalt K. Universal screening of social determinants of health at a large US Academic Medical Center, 2018. Am J Public Health. 2020;110(S2):S219-S21.

196. Southby K, Gamsu M. Factors affecting general practice collaboration with voluntary and community sector organisations. Health Soc Care Community. 2018:26(3):e360-e9.
197. Williams-Roberts H, Neudorf C, Abonyi S, Cushon J, Muhajarine N. Facilitators and barriers of sociodemographic data collection in Canadian health care settings: a multisite case study evaluation. Int J Equity Health. 2018;17(1):186.

198. Bloch G, Rozmovits L, Giambrone B. Barriers to primary care responsiveness to poverty as a risk factor for health. BMC Fam Pract. 2011;12(1):62.

199. Valaitis R, Cleghorn L, Ploeg J, Risdon C, Mangin D, Dolovich L, et al. Disconnected relationships between primary care and communitybased health and social services and system navigation for older adults: a qualitative descriptive study. BMC Fam Pract. 2020;21(1):69.

200. Messmer E, Brochier A, Joseph M, Tripodis Y, Garg A. Impact of an on-site versus remote patient navigator on pediatricians' referrals and families' receipt of resources for unmet social needs. J Prim Care Community Health. 2020;11:2150132720924252.

201. Moffatt S, Steer M, Lawson S, Penn L, O'Brien N. Link worker social prescribing to improve health and well-being for people with longterm conditions: qualitative study of service user perceptions. BMJ Open. 2017;7(7):e015203.

202. Mercer SW, Fitzpatrick B, Grant L, Chng NR, McConnachie A, Bakhshi A, et al. Effectiveness of community-links practitioners in areas of high socioeconomic deprivation. Ann Fam Med. 2019;17(6):518-25.

203. Sege R, Preer G, Morton SJ, Cabral H, Morakinyo O, Lee V, et al. Medical-legal strategies to improve infant health care: a randomized trial. Pediatrics. 2015;136(1):97-106.

204. Frostick C, Bertotti M. The frontline of social prescribing - how do we ensure Link Workers can work safely and effectively within primary care? Chronic Illness. 2019. https://doi.org/10.1177/1742395319 882068.

205. Herrera CN, Brochier A, Pellicer M, Garg A, Drainoni ML. Implementing social determinants of health screening at community health centers: clinician and staff perspectives. J Prim Care Community Health. 2019;10:2150132719887260.

206. Kung A, Cheung T, Knox M, Willard-Grace R, Halpern J, Olayiwola JN, et al. Capacity to address social needs affects primary care clinician burnout. Ann Fam Med. 2019;17(6):487-94.

207. Pantell MS, De Marchis E, Bueno A, Gottlieb LM. Practice capacity to address patients' social needs and physician satisfaction and perceived quality of care. Ann Fam Med. 2019:17(1):42-5.

208. Krska J, Palmer S, Dalzell-Brown A, Nicholl P. Evaluation of welfare advice in primary care: effect on practice workload and prescribing for mental health. Prim Health Care Res Dev. 2013;14(3):307-14.

209. Hsu C, Hertel E, Johnson E, Cahill C, Lozano P, Ross TR, et al. Evaluation of the learning to integrate neighborhoods and clinical care project: findings from implementing a New lay role into primary care teams to address social determinants of health. Perm. 2018;22:18-101.

210. Garg A, Sarkar S, Marino M, Onie R, Solomon BS. Linking urban families to community resources in the context of pediatric primary care. Patient Educ Couns. 2010;79(2):251-4.

211. Wildman JM, Moffatt S, Penn L, O'Brien N, Steer M, Hill C. Link workers' perspectives on factors enabling and preventing client engagement with social prescribing. Health Soc Care Community. 2019;27(4):991-8.

212. Poverty and child health in the United States. Pediatrics. 2016:peds.2016-0339.

213. Daniel H, Bornstein S, Kane G, Physicians ftHaPPCotACo. Addressing social determinants to improve patient care and promote health equity: an American College of Physicians Position Paper. Ann Intern Med. 2018;168(8):577-8.

214. Butkus R, Rapp K, Cooney TG, Engel LS. Envisioning a better U.S. health care system for all: reducing barriers to care and addressing social determinants of health. Ann Intern Med. 2020;172(2 Supplement):S50-S9.

215. Futures. IfA. Community health centers leveraging the social determinants of health. Alexandria: Institute for Alternative Futures; 2012

216. Human Rescources \& Services Administration. Federally qualified health centers. Available from: https://www.hrsa.gov/opa/eligibilityand-registration/health-centers/fqhc/index.html. Accessed 17 Sept 2021.

217. Draayer A. Integrating social health data to improve care delivery and address social needs. Boston: Health Leads; 2018. 
218. Garg A, Butz AM, Dworkin PH, Lewis RA, Serwint JR. Screening for basic social needs at a medical home for low-income children. Clin Pediatr (Phila). 2009;48(1):32-6.

219. Chung EK, Siegel BS, Garg A, Conroy K, Gross RS, Long DA, et al. Screening for social determinants of health among children and families living in poverty: a guide for clinicians. Curr Probl Pediatr Adolesc Health Care. 2016;46(5):135-53.

220. Garg A, Marino M, Vikani AR, Solomon BS. Addressing families' unmet social needs within pediatric primary care: the health leads model. Clin Pediatr (Phila). 2012;51(12):1191-3.

221. Moffett ML, Kaufman A, Bazemore A. Community health workers bring cost savings to patient-centered medical homes. J Community Health. 2018;43(1):1-3.

222. Huffstetler AN, Phillips RL Jr. Payment structures that support social care integration with clinical care: social deprivation indices and novel payment models. Am J Prev Med. 2019;57(6 Suppl 1):S82-S8.

223. Pruitt Z, Emechebe N, Quast T, Taylor P, Bryant K. Expenditure reductions associated with a social service referral program. Popul Health Manag. 2018;21(6):469-76.

224. Schickedanz A, Sharp A, Hu YR, Shah NR, Adams JL, Francis D, et al. Impact of social needs navigation on utilization among high utilizers in a large integrated health system: a quasi-experimental study. J Gen Intern Med. 2019;34(11):2382-9.

225. Vasan A, Morgan JW, Mitra N, Xu C, Long JA, Asch DA, et al. Effects of a standardized community health worker intervention on hospitalization among disadvantaged patients with multiple chronic conditions: a pooled analysis of three clinical trials. Health Serv Res. 2020;08:08.

226. Fiori KP, Heller CG, Rehm CD, Parsons A, Flattau A, Braganza S, et al. Unmet social needs and no-show visits in primary care in a US northeastern urban health system, 2018-2019. Am J Public Health. 2020;110:S242-S50.

227. Gottlieb L, Ackerman S, Wing H, Manchanda R. Understanding Medicaid managed care investments in members' social determinants of health. Popul Health Manag. 2017:20(4):302-8.

228. The accountable health communities health-related social needs screening tool. In: Services CfMM, editor.: Centers for Medicare \& Medicaid Services.

229. Gottlieb LM, Quinones-Rivera A, Manchanda R, Wing H, Ackerman S. States' influences on medicaid investments to address patients' social needs. Am J Prev Med. 2017;52(1):31-7.

230. Gottlieb L, Razon N, Aboelata N. How do safety net clinics pay for social care programs? 2019

231. Harding R, Sherr L, Sherr A, Moorhead R, Singh S. Welfare rights advice in primary care: prevalence, processes and specialist provision. Fam Pract. 2003;20(1):48-53.

232. Parry J. A prescription for poverty. Br Med J. 2016;353:i3370.

233. Buitron de la Vega P, Losi S, Sprague Martinez L, Bovell-Ammon A, Garg A, James T, et al. Implementing an EHR-based screening and referral system to address social determinants of health in primary care. Med Care. 2019;57(Suppl 6 Suppl 2):S133-S9.

234. Cantor MN, Thorpe L. Integrating data on social determinants of health into electronic health records. Health Aff. 2018;37(4):585-90.

\section{Publisher's Note}

Springer Nature remains neutral with regard to jurisdictional claims in published maps and institutional affiliations.
Ready to submit your research? Choose BMC and benefit from:

- fast, convenient online submission

- thorough peer review by experienced researchers in your field

- rapid publication on acceptance

- support for research data, including large and complex data types

- gold Open Access which fosters wider collaboration and increased citations

- maximum visibility for your research: over $100 \mathrm{M}$ website views per year

At BMC, research is always in progress.

Learn more biomedcentral.com/submissions 